\title{
COMUNICACIÓN ALTERNATIVA: ANTE LAS ENCRUCIJADAS DEL DISCURSO DESARROLLISTA
}

\section{ALTERNATIVE COMMUNICATION: DEVELOPMENT AND MODERNIZATION}

\author{
Páginas: Carlos Eduardo Valenzuela Echeverri \\ 44-56 duardocoldyahoo.com \\ Especialista en Comunicación-Educación. \\ 22 de \\ El artículo es producto del proyecto \\ Aceptado: de investigación titulado "Nociones de \\ 08 de mayo periodismo en medios alternativos y \\ comunitarios de Bogotá" de la Fundación
}

Universitaria Los Libertadores.
Resumen

La pregunta por el estatuto de la comunicación alternativa se encuentra, en buena medida subordinada, como ocurre en general con cualquier categoría cuya densidad teórica interesa rastrear, a examen de su génesis, a la auscultación de sus condiciones históricas de posibilidad y concreción. De allí, el énfasis del presente artículo, cuyo objeto no es otro que el de visibilizar la importancia de la comunicación alternativa en la consolidación del sentido de lo comunitario y la cohesión social, en una mirada retrospectiva, respecto de lo escenarios contextuales que rodearon la emergencia de un enfoque comunicativo que marcó la diferencia en relación con los

procesos de comunicación hegemónicos, detentados por la tradición desarrollista y la modernización.

Palabras clave Comunicación alternativa, desarrollo, modernización, teorías de la dependencia, democracia.

\section{Abstract}

The question of the status of alternative communication is often subordinate, as happen in general with any interested category whose theoretical density we want to track, to the examination of its genesis, and auscultation of the historical conditions of possibility and realization. From there, the focus of this article is simply to make visible the importance of alternative

communication in strengthening the sense of community and social cohesion, in retrospect for contextual scenarios surrounding the emergence of a communicative approach that made the difference in relation to the processes of hegemonic communication held by the developmentalist tradition and modernization.

Keywords

Alternative communication, development,

modernization, theories of dependency,

democracy. 


\section{Introducción}

Claramente el apelativo de alternativa que solemos atribuirle al tipo de comunicación que se caracteriza por fomentar, cultivar y defender la expresión de aquellos a quienes se les ha der la expresión de aquellos a quienes se les ha
negado en virtud de su condición de opriminegado en virtud de su condición de oprimidos; de subalternos subordinados al poderío del capital y a los mensajes producidos por los de masas, aparece para hacerle frente a una manera de asumir y entender la comunir manera de asumiry entender lo cerios siglos. De modo que, a la par del interés por hablar acerca del matiz alternativo que le conferimos a una comunicación hecha para "suplir las necesidades de expresión de segmentos de las clases subalternas en sus luchas por el establecimiento de la justicia social" (Krohling Peruzzo 2012, p. 367), se hace necesario tam aludir al carácter de esa otra comunicación en razón de la cual existe justamente la alternativa

Nos referimos a la comunicación cuyo espíritu apalancó el proyecto modernizador de la era industrial y civilizatoria. Una comunicación puesta al servicio de una cierta idea de mundo que se propagó a lo largo y ancho del territorio occidental. A decir verdad, sus réditos se miden hoy por hoy a partir de los aportes hechos al ascenso a nivel mundial de una lógica sociopolítica basada en los valores del mercado la globalización y la sociedad de consumo. En otras palabras, estamos hablando de una perspectiva de sociedad que, en buena medida, fró en la comunicaci sión, de su mater sión, de su materialización en términos de un sociedad supeditada a los regímenes del lucro y al ansia de desarrollo.

A esta vertiente, tildada por muchos de modernizadora, enfrentamos nosotros la perspectiva progresista de la comunicación. Aquella de la que nos interesa reflexionar en este artículo, no sin hacer antes, por supuesto, un sencillo recuento a propósito del marco contextual o condiciones históricas que, podríamos decir, precipitaron al cabo del tiempo la emergencia de lo que en los años setenta y los ochenta se dio en llamar comunicación "alternativa": fuente de resistencia ideológica, cuyo empeño por contrarrestar el afán modernizador de la sociedad imperante, la hizo acreedora de un aguzad concederle un rostro simbólico que hubo de definirse gracias al deseo por mostrar, precidefire por mostrar, precisamente, el de aquellos que el desarrollismo rezagó, enmudeciendo su voz al restarle valor a su expresión

Así pues, poner de relieve y cartografiar el suelo nutricio que, podríamos decir, inspiró la aparición de esta perspectiva de comunicación, entronca muy bien con el objetivo que se trazó el proyecto: "Nociones de periodismo en medios alternativos y comunitarios de Bogotá"1 de ahondar en los referentes ideológicos, teóricos e históricos que vehiculizaron y aún insuflan el quehacer periodístico de quienes se han dedicado a informar desde una orilla disidente y alternativa a la del establecimiento. Accionar sobre cuyo ethos, el proyecto en cuestión acentúa su mirada con el fin de analizar y caracterizar el tipo de propuestas y discursos, en razón del cual diversos medios en Bogotá buscan hacer comunicación desde y con la comunidad, en aras de reivindicar el sentido de lo público, el valor de la ciudadanía y el poder de la cohesión social y la democracia. En este terreno ce discusión, es donde se instalaran las reflexiones que vien donde se instalarán arreglo al siguiente itinerario temático.

Del que deriva el presente artículo y al que aporta en virtud de la conceptualización que elleva a cabo a propósitio de las
En las dos primeras partes del presente artículo, se arriesga una suerte de retrospectiva histórica a propósito del papel de lo comunicativo en el ascenso del paradigma occidenta moderno, con el fin de sopesar, posteriormente, la importancia que reviste la comunicación alternativa para quienes se piensan el mundo desde vectores distintos a los marcados por las grandes estructuras, las lógicas desarrollistas y el capitalismo a ultranza.

\section{Comunicación: baluarte de progreso}

El interés por lo comunicativo, en tanto plataforma de despegue del sueño ilustrado y la industrialización, se hizo especialmente evidente a finales del siglo XVIII, en virtud del propósito que los científicos de la época le atribuyeron a la comunicación: "organizar el trabajo colectivo en el seno de la fábrica y en la estructuración de los espacios económicos" (Mattelart, 1997, p. 14) Así, la comunicación pasó a constituirse, en buena medida, en la columna vertebral del proyecto expansionista de la era industrial, al favorecer los principios económicos propios de la ilustración; principios que, de modo paulatino, fueron finalmente extendiéndose a lo largo de toda Europa.

$\mathrm{Al}$ amparo de tales presupuestos de progreso y racionalización del mundo moderno, la comunicación, leída en calidad de medio de transporte fluvial, marítimo y terrestre, reportará en esencia una función de carácter económico, cuyo refinamiento dependerá de los aportes de diversas ciencias que le abordarán con fines utilitaristas, buscando contribuir a la flexibilización de los flujos de bienes y al crecimiento de la mano de obra en favor del sistema fabril. En ese orden de ideas, pensar en la comunicación como aliada del advenimiento político, económico e industrial de la sociedad moderna, le marcará un sino flanqueado por intereses de índole diversa, en especial de carácter corporativista y político, a los que la comunicación no cesará de plegarse, como bien se atestigua en la contemporaneidad. Esta concepción de la comunicación al servicio de lo económico hará de aquella un objeto de suma importancia para los economistas decimonónicos, quienes, al estudiarla, privilegiaran conceptos extraídos de las ciencias naturales como: sistema, unidad, flujo, red, en fin. De hecho, la idea concreta de organismo-red (Musso, 1990 citado por Mattelart, 1997) se erige como referente para pensarse lo social desde matrices interpretativas distintas: la sociedad en tanto sistema orgánico, leído a partir de claves biologicistas, fisicalistas etcétera, pero con asiento de forma evidente en lo económico. De este modo, los flujos de capital, las redes de comercio y aquellas vías de interconexión que posibilitarían vínculos económicos a gran escala, adquirirán la misma importancia para la sociedad industrial que el sistema circulatorio para el cuerpo humano.

Este estado de cosas, que claramente responde a la lógica del industrialismo, acorde con los pre como la sed positiva: "la funcón se conocerá de la producción de las redes artificiales, las de la comunicación-transporte (las redes materiales) y las del mundo financiero (las redes espirituales). Crean líneas de ferrocarril, sociedades de banca y compañías marítimas” (Mattelart 1997, p. 15). El florecimiento de esta filosofía auspiciadora del espíritu de empresa de la segunda mitad del siglo XIX, incidirá de modo notable entre aquellos que se piensan la comunicación, como Herbert Spencer, fisiólogo social, quien contribuirá a reflexionar sobre la comunicación bajo criterios estrictamente biologicistas, llevando al extremo la analogía entre sistema orgánico y sociedad: 

Una sociedad-organismo cada vez más coherente e integrada, donde las funciones son cada vez más definidas y las partes cada vez más interdependientes. En este todo-sistema, la comunicación es un componente básico de los dos aparatos de órganos, el distribuidor y e regulador. A semejanza del sistema vascular, el primero (carreteras, canales y ferrocarriles) asegura la conducción de la sustancia nutritiva. El segundo asegura el equivalente de la función de sistema nervioso; posibilita la gestión de las relaciones complejas de un centro dominante con su peri tro dominante con su periferia. Es la tarea de los informativos (prensa, solicitudes, encuestas) y del conjunto de los medios de comunicación gracias a los cuales el centro puede propagar su in fluencia (correos, telégrafo, agencias de prensa). Se comparan las noticias con descargas nerviosas que comunican un movimiento de un dad al de otra (Mattelart, 1997, p. 16).

En tal contexto, el sentido de la comunicación permanecerá restringido, en consecuencia, no solo al carácter capitalista de la época, sino también a una lectura disciplinar igual de restrictiva, en tanto hace de la comunicación un simple componente funcional a un mecanismo-sistema, comandado por la fiebre de la industrialización y el sueño del progreso y el desarrollo.

Hasta aquí, pese a lo general del esbozo, se alcanza a percibir el decisivo papel que la comunicación jugó en la consolidación de un proyec to de sociedad: el occidental, que finalmente sembró sus esperanzas en una hipótesis muy sugestiva equivalente a la idea de un desarrollo sin límites, fundado en el convencimiento de que lo económico constituiría la base de un avance social sin precedentes. El influjo de esta perspectiva clausurará, a lo largo de muchos años, iniciativas políticas y culturales de diversa índole, refractarias, por supuesto, al credo desarrollista defendido por occidente y su sistema-mundo; evangelio que, como veremos a continuación, arraigó de forma paulatidida, a la comunicación, en los territorios que se encontraban bajo la égida del pensamiento modernizador y la industrialización.

\section{Desarrollo y comunicación}

Hablar acerca de la comunicación para el desarrollo es tanto como hablar respecto de los después de la Segunda Guerra Mundial, crearon alrededor de los países más pobres. Aquelos sobre los que se trazó toda una estrategia de intervención a muy diversa escala, cuya de intervención a muy diversa escala, cuya nnalidad radicaba básicamente en "que los pobres fueran un poco menos pobres, para que su poder adquisitivo les permitiera convertirse en consumidores" (Gumucio, 2012, p. 26). En tal medida, fue que los modelos de comunicación dernizaci to de “apoyar la expansión de los mercadosconsumo y la a mimión de los mercados de marginados de la sociedad” (p. 26).

Pero, ¿y a qué propósitos terminaron por servir las herramientas de comunicación empleadas por los países desarrollados al b hacer extensivo a los demás territorios del mundo su propio modelo de sociedad? ¿Cómo reaccionan tales países frente a la arremetida deológica del bloque desarrollado que busca dominarles? ¿Qué idea de comunicación, por lo tanto, se hace necesario engendrar para contrarrestar el poder de persuasión y aculna y con mucha fuerza, gracias, en buena meintereses que las naciones industrializadas, turación que los territorios hegemónicos comienzan a ejercer sobre sus vecinos más pobres? Volvamos entonces, con mayor detalle, sobre estas cuestiones.

Evidentemente, como se hizo ostensible al principio de este texto, la consigna del desarrollo ha sido una constante que no ha dejado de acompañar a la empresa moderna desde su propia génesis; no obstante, dicho discurso soarrollo obtiene, posterior a la Segunda Guerra Mundial, un pospardarazo por parte de Estados Unidos tun furte que por parte de Estados Unidos tan fuerte que logra un
nivel de reificación sumamente alto, lo que lo convierte en un verdadero fetiche ${ }^{2}$ : el fetiche del desarrollo. Objeto al que, desde el momento de su reificación, se plegarán, de modo incondicional, los medios de comunicación masivos y las nuevas tecnologías en atención a la injerencia que sobre ellos ejerce la hegemonía de los países industrializados.

En efecto, hace ya más de cincuenta años, la noción de desarrollo introducida por Estados Unidos en el escenario de la política transnacional, a través del presidente Harry Truman en su discurso de investidura (Esteva Gustavo, 1996) no solo otorgó peso, forma y propósito a las prácticas y sistemas que durante mucho tiempo y aún, diferencialmente, han ejercido dominio sobre el mundo (Sbert José, 1996) sino que, de igual modo, significó y dio consistencia a la noción de subdesarrollo, cuya lógica se difundió de manera generalizada sobre los países denominados “tercer mundistas", atención al etiquetado de primer-mundistas

2 Los objetos fetiche "son aquellos que han sido ratificados por que [se denomina fetichel, en atención a que no se trata de un nombre de la cosa, sino de un efecto de significación que está en lugar de ela cosa, y que pe convierte en un atractivo, al pu fetiches han llegado a producirse" Mimeo Bustamante, G. et al. (2014) “Hacia una teoría del campo (Bourdieu), a propósito de las tesis de los estudiantes del programa de psicolo atribuido a los países considerados desarrolla-

La polisemia del vocablo desarrollo sirvió de telón de fondo para matizarlo con nuevas y renovadas acepciones que permitiesen legitimar acciones y discursos tendientes a conducir el pensamiento y racionalizar la conducta desde ógicas visiblemente economicistas. La ambigüedad semántica denotada por dicho concepto le concedió a quienes lo profesaron en la administración Truman -Lewis, Rostow, Baranla oportunidad de hablar aparentemente con propiedad respecto del tema, adjudicándose a su vez el derecho de decidir qué y quiénes ameritaban, en razón de sus "necesidades" y carencias económicas (Iván Illich, Sbert José, 1996), su respaldo tecnológico y político-económico. De esta forma, se da pie a argumentar que, con el apoyo de los medios y las nuevas tecnologías en las regiones más desfavorecidas, será posible modernizar a los campesinos analfabetos que se hallan sumidos en la ignorancia.

Esta premisa implica que el conocimiento es un privilegio exclusivo de los países industrializados y que, por lo tanto, la transferencia de información mejorará las vidas de los pobres. El postulado subyacente es que los pobres son pobres debido a un déficit de conocimiento: si los pobres del mundo pudieran acceder a la información sobre el desarrollo, estarían en condiciones de producir más, aumentar sus ingresos, integrarse a la sociedad y ser más felices (Gumucio, 2012, p. 28) 
Así pues, lo que se transfirió no fue más y me- hombre moderno y su fe ciega en el progreso jor conocimier jor conoci pregonaban los discursos de los desarrollistas, llo, sed que interiorizaron millones de personas, buscando saciarla a través de un único modo: el consumo de bienes y servicios y la industrialización (Gustavo Esteva, 1996). Dicha creencia, propalada a lo largo y ancho del tercer mundo mediante la estrategia denominada "comu hecha consigna por los políticos de turno quienes le usufructuaron para alentar su supuest “aventura hacia el progreso", razón de ser de sus programas de gobierno, adscritos por supuesto al paradigma de modernización patrocinado por los países desarrollados.

De este modo, la convicción de hacer partícipes a los países de la periferia del acumulado tecnológico y el potencial de innovación de Estados Unidos y Europa implicó la emergencia de un paradigma comunicativo capaz de contribuir a la difusión e inmediata apropiación de la tesis esencial del discurso desarrollista, según la cual "para formar parte del mundo moderno, las comunidades rurales y suburbanas de los países del Tercer Mundo necesitan dejar atrás sus tradiciones y adoptar los medios masivos de difusión y las nuevas tecnologías de occidente” (Gumucio, 2012, p. 28-29). De fondo, fue este el sentido político que inspiró la creación de esta corriente comunicativa para el desarrollo en 1962, cuyo autor fue Everett Rogers quien, después de catorce años e influenciado por intelectuales de América Latina acabó reevaluando sus postulados y engrosando las filas de los detractores del paradigma dominante.

Ahora bien, pese a que hubo quienes combatieron sin cuartel y con sólidos argumentos, la fuerte dependencia de los países no industrializados al paradigma dominante, la noción del fue naturalizándose de manera paulatina, hallando asidero en miles de hogares procedentes del considerado mundo pre-moderno, cuya cultura local, en el mejor de los casos, se tornó funcional al desarrollo económico global, no quedándoles, según Ayres y su teoría del progreso económico: “...más alternativa que aceptar inteligente y voluntariamente el modo de ial y todos los valores que lo acompañan” (Citado por José María Sbert, 1996, p. $302)$

El modelo de difusión de innovaciones planteado por Rogers se aplicó desde la década del sesenta principalmente en la agricultura, porque los países donantes percibían que la productividad agrícola era la prioridad para el desarrollo. El incremento de la producción mediante la introducción de nuevas tecnologías no solo menguaría el hambre en el Tercer Mundo, sino que los excedentes abastecerían de productos agrícolas baratos a los países industrializados. Lo que hemos conocido en esos años como repúblicas bananeras, con sus implicaciones económicas, sociales y políticas, es una expresión de esa estrategia de desarrollo (Gumucio, 2012, p. 30)

Estrategia de desarrollo que no hizo más que eludir la singular cosmovisión de un sinnúmero de culturas confinadas al régimen de lo masivo, con el fin de instalar en ellas la lógica hegemónica del desarrollismo instaurada por el pensamiento occidental Así no solo se legitimó una forma de vida social, la industrialización, sino que también se legitimaron "unas" prácticas, "unos" discursos y "unas" maneras modernas de ser, sentir y pensar, dominantes, en detrimento de otras cuyos valores, ritos, historicidades y tradiciones dejaron de ser "visibles", subalternándose para extinguirse o di- luirse en las veleidades del sistema capitalista y el hombre moderno.

El enunciado subyacente es que las tradiciones culturales en los países más pobres son taras que impiden que las personas vivan mejor. Las culturas locales son vistas como barreras para la modernización y la cohesión colectiva retrasa los cambios de actitud, razón por la cual ciertos individuos son seleccionados como campeones del cambio en su propia comunidad (Gumucio,
2012, p. 32)

De este modo, al detentar un único destino para las naciones más pobres, la autoridad de la cual se autorevistieron los promotores del fenómeno desarrollista parecía "natural", atávica y, por consiguiente, indiscutible. De hecho, los argumentos a favor de tales posicionamientos avalaban tesis que aunque enarbolaban lo colectivo, solo lo hacían en función de justificar la arbitrariedad de pensar en la id de un mismo horizonte para todos:

En sus orígenes, las sociedades tienden a legitimar sus identidades de forma que escapen al debate y a la revocación por parte de los socios. por parte de los socios. La autoridad de lo colectivo se sitúa en un plano indiscutible y omnipotente: sea la voluntad de los dioses o de los ancestros que nos han hecho ser como somos, sea nuestra propia "naturaleza" comunitaria que nos determina sin apelación (Savater, 1995, p. 163).

De acuerdo con tales presupuestos, la legitimidad atribuida al desarrollo convertía la práctica cultural discordante, rebelde y convencional de los diversos pueblos considerados tercermundistas, en un flagrante desacierto que, de seguir auspiciándose, arruinaría el que, de s cometido de contribuir a la transformación de estas sociedades a las que se les inculcó el maginario del renacer en nombre del desarrollo. Así pues, como efecto de estas dinámicas de persuasión, la idea del resurgimiento, amparada en el sueño del hombre prometeico “[...] verdadero demiurgo, dueño de sí mismo, de la naturaleza y del universo, capaz, gracias al sometimiento de los recursos que lo rodean, de realizar un crecimiento exponencial de la producción, del consumo, de los placeres de la vida, hacia un horizonte sin límites, no cerrado" (Abdel-Malek citado por Arocena José, 1995, p. 10), pasó a ser, en última instancia, pese a múltiples consideraciones de orden social y cultural promulgadas por diferentes voces, la razón de ser del modelo occidental moderno. Como saldo principal, esta postura arrojó el patrocinio de una idea de desarrollo correlativa exclusivamente a una forma de crecimiento económico, cuya configuración unilateral clásica ha girado fundamentalmente en torno a la producción, el trabajo, el costo, las ganancias y las necesidades, invisibilizando esferas de muy diversa indole que incidirían notablemente en una noción mucho más compleja de desarrollo.

De esta forma, sobre los anteriores supuestos relativos al orden mundial deseado por la empresa modernizadora de occidente, se apoyará, al menos en una primera etapa, el paradigma de la comunicación para el desarrollo corriente que, renuente a abandonar su rol difusor de innovaciones a través de los medios masivos, no renunciará a la posibilidad de aminorar, mediante nuevas estrategias comunicativas, su marcado verticalismo con el objeto de acaparar de manera más eficiente la atención de las personas. 
Frente a lo anterior, cabe ahora evocar el marco contextual que contribuyó a la emergencia de una perspectiva de comunicación divorciada de aquellos principios defendidos por el desarrollismo y duramente enjuiciados por las teorías de la dependencia. Me refiero a la perspectiva de la comunicación alternativa, enfoque que emerge como respuesta a la intencionalidad de aportar al objetivo de que las comunidades y grupos dominados se apropien de los procesos de comunicación. Veamos ahora el despliegue de tal vertiente y sus implicaciones.

\section{Comunicación alternativa: una apuesta por la apropiación}

Como réplica al discurso desarrollista promovido por los países industrializados, diversos intelectuales de las regiones periféricas entraron a cuestionar los postulados que cimentaban el ideario de modernización. Plegarse a hecho de asumir la pobreza como mero efecto de la ignorancia y como resultado de la nuencia al cambio cultural, al margen de las desigua desigualdades sociales y la miopla del sistema global, era tanto como aceptar culpar a los grupos dominados de ser artífices exclusivos de su propia opresión. Si bien fue haciéndose evidente que restarles responsabilidad a las masas respecto de su estado de sujecion a poder hegemónico no era del todo consecuente con la idea de entender la opresión "como actividad del oprimido" (Martín Barbero, 2003, p. 111) y, en consecuencia, su propia responsabilidad, tampoco era factible soslayar el nivel de incidencia de las grandes estructuras en la situación de determinación de los países más pobres.

Esta postura, que puso en tela de juicio los pivotes del ideario desarrollista, tuvo eco dentro de las denominadas teorías de la dependencia: corriente que deconstruyó la comunicación para el desarrollo, en tanto le trazó un derrotero distinto al atribuido por los académicos de norte. El rumbo adjudicado fue el de la eman-

papel en relación con el desmantelamiento progresivo de las teorías de la modernización y su paradigma verticalista, al punto que muchos de los pioneros de la comunicación para el desarrollo -como Luis Ramiro Beltrán, el de su credo y fungieron en calidad de promotores de la comunicación como derecho ciudadano.

Así pues, al par de nombres citados, se sumará un extenso listado de autores latinoamericanos, asiáticos y africanos entre los que Cardoso, Darcy Ribero, María da Conceicao Tavares, Theotonio dos Santos, Juan Gamias, Gloria Feliciano, Florangel Rosario-Braid, Frank Ugboajah, el mismísimo Paulo Freire (Gumucio, 2012), en fin, toda una caravana de librepensadores adscritos a las teorías de la dependencia que fueron capaces de leer el subdesarrollo por encima del ángulo estrecho y xenófobo promulgado por el norte y parte de Europa.

Los argumentos que esgrimieron en dirección a problematizar las supuestas causas del subdesarrollo en los países mal llamados del tercer mundo radicaban en denunciar la injerencia de un Estado opresor al servicio de un régimen político, económico, social y cu raya de las demandas de los pueblos, sublevados en razón del escaso margen de acción democrática al que les reducían.

No era casual que los pueblos se sublevaran exigiendo una participación en la vida democrática. La militancia política vida democrática. La milicancia politica en las calles y en las organizaciones sociales permitió el surgimiento de experiencias de comunicación alternativa y participativa, tanto urbanas como rurales, cuyo principal objetivo era conquistar espacios de expresión y empoderar a las voces colectivas. Se conoce con diversos nombres a esas experiencias de comunicación: popular dialógica, alternativa, participativa, endógena, comunitaria... (Gumucio, 2012, p. 37).

Y a pesar de la multiplicidad de denominaciones, lo que aunó y aún congrega a estas distintas experiencias comunicativas es propender por la transformación del "proceso, la forma dominante y normal de la comunicación social, para que sean las clases y los grupos dominados los que tomen la palabra” (Bosco, 1998; Pinto citado por Martín Barbero, 2003, p. 117-118), fin último de la comunicación alternativa, en tanto de generar escenarios de expresión en medio del mutismo impuesto por los regimenes neoliberales y dictatoriales. Escenarios hechos no solo de artefactos de comunicación a los que accedían los grupos subalternos ante el portazo recibido por parte de los medios masivos de difusión estatales o privados, sino, y principalmente, hechos del inpopular se traduce en hacer "[...] posible la expresión de las aspiraciones y expectativas colectivas producidas por y desde los grupos sociales de base. Tanto mayoritarios como minoritarios, tanto a nivel patente como latente" (Beneyto 1979, citado por Martín Barbero, 2003, p. 118) En esa medida, reducir lo alternativo al medio en sí mismo, sin que ello quiera decir renunciar a la posibilidad de involucrar al medio masivo, constituye una acción que parece no relevar el acento que la comunicación alternativa pone sobre la apropiación de los procesos comunicativos, pues, en ello se cifra el sentido de lo alternativo: en la posibilidad de aportar no solo al acceso, sino al empoderamiento o, mejor sería decir, al potenciamiento de la autonomía del sujeto en función de fortalecer, desce dive la importancia de lo comunitaio. Movimiento que implica, dado lo que alĺ se juega en terminos in mosicionar a los actores en calidad de gestores, un ejercicio formativo evidente, del que no nos es posible desentendernos si aspiramos a superar el umbral de la simple capacitación o el uso de artefactos a la hora de comunicar:

El rasgo central de la comunicación alternativa es la apropiación de los procesos de comunicación. apropiación se debe entender como el desarrollo de la capacidad autónoma y colectiva de adoptar la comunicación como herramienta que contribuye al fortalecimiento organizativo comunitario. El concepto va más allá de la propiedad de los medios y del manejo de la tecnología; no se trata simplemente de convertirse en propietarios de una estación de radio, un periódico o un canal de televisión, sino de apropiarse del proceso de toma de decisiones, como una respuesta colectiva a la hegemonía y a la imposibilidad de acceder a los medios masivos (Gumucio, 2012, p. 38).

En tal medida, hablar de comunicación alternativa no equivale simplemente a hablar de medios e instrumentos cuya novedad es lo considerado "alternativo" por las supuestas posibilidades dialógicas que abre. La comuni- 
cación no es algo restringible netamente al instrumental que la hace posible. Además, comunicar supone creación de sentido y, en conse cuencia, producción de realidad. Una realidad cuya configuración depende del lenguaje que empleamos para "describirla” o, diríamos más bien, para construirla.

Este carácter fundante del lenguaje nos permite inferir la importancia que reporta la comunicación para quienes constituimos sociedad. Por lo tanto, su veto cercena el impulso por construir una democracia que contrarreste el individualismo de la ideología capitalista imperante y propenda más por "la liberación del habla, de la actividad y la creatividad popular que [por] el tipo de medios utilizados" (Martín Barbero, 2003, p. 118).

Así pues, contra la censura, contra el despotismo, contra el individualismo, contra el autoritarismo insuflado por el ideario desarrollista de modernización a lo largo de centurias, aparece la comunicación alternativa, enfoque "constituido por iniciativas populares (del pueblo) en el contexto de localidades barrios, comunidades (presenciales o virtuales), movimientos sociales y organizaciones civiles movimientos sociales y organizaciones civiles congéneres sin fines lucrativos" (Krohling Pe ruzzo, 2012, p. 367). Dicha vertiente termina por configurar todo un paradigma comunicacional al que deciden adscribirse todos aquellos interesados por combatir la desigualdad social, a partir de propuestas que rebasan la talan en la dinamica de alentar prácticas que involucran el uso de los medios en función de suscitar el diálogo con y entre las personas, no sobre ellas, como estilan los medios masivos. De este modo y de acuerdo con lo anterior:

[...] podríamos hablar de la comunicación popular como un gran impulso ético y de responsabilidad con los más desposeídos, en diálogo participativo con ellos para su liberación. Este es el gran rescate de una experiencia que sigue siendo viable en algunos de sus principios valóricos básicos, dentro de una línea de renovación. La comunicación no fue un elemento accesorio ni un instrumento, era el lugar de los procesos de transformacion. Si bien esta comprensión tiene algo de romántico podemos destacar hoy que ella puso el dedo en una valoración de este campo por la comunicación misma. Es decir, que se apostaba por los diálogos que se lograban procesar y los enriquecimientos educativos que de allí surgían (Alfaro Moreno, 2000).

En las palabras de Alfaro, habrán notado un cierto dejo de nostalgia en relación con la fico de una contemporaneidad convulsa como la nuestra; contexto gubacis esta "con, contexto globalizado, para el cual, esta "comunicación otra" viene a toparse con otras lógicas que retan la singular ideología de resistencia que alimentó el horizonte teórico combativo y reivindicativo sobre el que se erigió esta vertiente comunicacional.

Hoy por hoy, en efecto, de acuerdo con la misma Alfaro y otros intelectuales de la comunicación, los dualismos que justificaron la lucha acérrima contra el poder imperante se desdibujaron ante la caída de los socialismos. Al individuo se le dejó de leer desde la óptica binaria contradictor/adepto; el fenómeno de lo popular y de lo masivo fueron objeto de imbricación que no resulta ya fácil deslindar; en fin, en palabras de la misma autora mencionada (2000) "[...] asistimos así a una época donde los sujetos son constreñidos a una gran reflexividad, replegándose hacia sí mismos y al proyecto propio en medio de un proceso de desterritorialización (sin fronteras) y de hibridación de las culturas".

\section{A modo de conclusión}

De acuerdo con lo anterior, cabe preguntar de qué carácter son las nuevas apuestas comunicacionales que orientan nuestro compromiso para con la sociedad y, en tal sentido, qué lugar atribuirle a un periodismo, como el alternativo, reacio a alinearse "con los estándares de los medios de comunicación convencionales, gobiernos y demás sectores que representan a las clases dominantes" (Krohling Peruzzo, 2012, p. 368)

A juzgar por los primeros indicios que empieza a arrojar la investigación en curso, el espíritu periodístico que alimenta el quehacer de las experiencias de comunicación alternativa estudiadas se caracteriza por no querer contrarrestar a gran escala los excesos de un poder como el del capital que nada tiene ya de monolito; no son de su interes las luchas que monolito; no son de su interés las luchas que en antaño propendían por transformar las grandes instituciones, a las que hoy leen con escepticismo, pese a tolerar su paquidérmico andar. No. Su vocación es otra. Y es la de enfatizar en las conquistas cotidianas de quienes enfrentan los efectos de aquello sobre lo que enfrentan los corectos de no dejan de teorizar intelectuales, políticos, estadistas y periodistas: la guerra, el conflicto, la crisis, el cambio de siglo, la pérdida de valores, en fin.

Así, la mirada está puesta sobre el circuito de micro-relaciones que a diario tejen aquellos sujetos cuya fe en el vínculo aún reivindica (pese a hacerlo en un escenario de no-lugares como aquel en el que se ha convertido la ciudad) el lugar del barrio, de la calle, del encuen- tro, del ocio; recodos donde se viene jugando, en el marco del trato, del pacto, el esta mo de la ciudadanía: una pensada muy al margen de los estereotipos que oferta actualmente el mercado a través de los medios masivos de comunicación

Este es el cariz que parece distinguir el accionar periodístico de estas experiencias comunicativas, a las que nos acercamos desde el proyecto de inve yulatina. Su lectura ha implicado el uso de una partitura de análisis distinta a la empleada por la ideología de las grandes utopías. No porque se haya renunciado de tajo a la viabilidad de tales ideales, sino porque su búsqueda ahora se cifra en el contexto de lo local, es decir, en el escenario donde efectivamente se dan cita quienes se preguntan al cohesiona, po principios de qu nos agutina. El sello que periodismo alta naturaleza le imprimen al periodismo alternativo oficiado en la actuaidad por este tipo de experiencias comporta una logica de acción que no comulga ni con los binarismos, como señalase Alfaro, ni con las reificaciones positivas a las que obedeció, en buena medida, la labor pionera del comunicador popular otrora.

Por supuesto, esta es una cuestión cuya discusión amerita ampliar el marco de análisis al que apenas si exhorta este texto. De allí, la importancia de continuar ahondando analítica y reflexivamente en las actuales experiencias de comunicación y periodismo alternativo gestándose en medio de las particularidades de la época presente, con el fin de desentrañar sus sentidos, sus rutas y, muy especialmente, sus prácticas de agenciamiento comunicativo. 


\section{Referencias}

Alfaro, R. "Culturas populares y comunicación participativa: En la ruta de las redefiniciones”. En revista Razón y Palabra. Recuperado de: www.razonypalabra.org.mx/anteriores/ n18/18ralfaro.html, consultado el 13 de febrero 2015.

Arocena, J. (1995). El desarrollo local: un desafío contemporáneo. Centro Latinoamericano de Economía Humana (CLAEH) Universidad Católica del Uruguay. Uruguay: Nuevo Siglo.

Esteva, G. (1996). Desarrollo. En: Diccionario del desarrollo. Una guía del conocimiento como poder. W. Sachs (Ed). Perú: PRATEC.

Gumucio, A. (2012) “Comunicación y cambio social: raíces ideológicas y horizontes teóricos”. En Comunicación y Desarrollo. Prácticas comunicativas y empoderamiento local. (Coords.) Martínez Marcelo y Sierra Francisco, Gedisa Editorial. España.

Illich, I. (1996). Necesidades. En: Diccionario del desarrollo. Una guía del conocimiento como poder. W. Sachs (Ed). Perú: PRATEC.

Krohling Peruzzo, C. (2012). "Aproximaciones entre la comunicación popular y comunitaria y la prensa alternativa en Brasil en la era del ciberespacio”. En Comunicación y Desarrollo. Prácticas comunicativas y empoderamiento local (Coords.) Martínez Marcelo y Sierra Francisco, España: Gedisa Editorial.

Martín-Barbero, J (2003) “Cultura: desafíos de lo popular a la razón dualista”. En Oficio de cartógrafo. Travesías latinoamericanas de la comunicación en la cultura. Colombia: Fondo de Cultura Económica.

Mattelart, A. \& Mattelart, M. (1997). Historia de las teorías de la comunicación. España: Paidós.

Savater, F. (1995). Diccionario filosófico. Bogotá: Planeta.

Sbert, J. (1996). Progreso. En: Diccionario del desarrollo. Una guía del conocimiento como poder. W. Sachs (Ed). Perú: PRATEC.

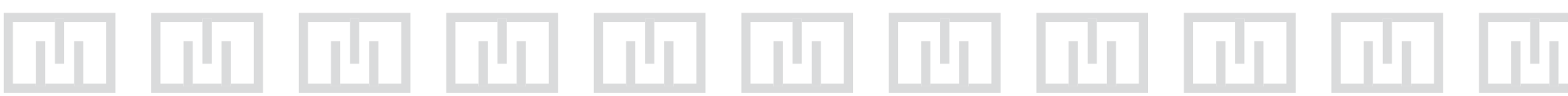

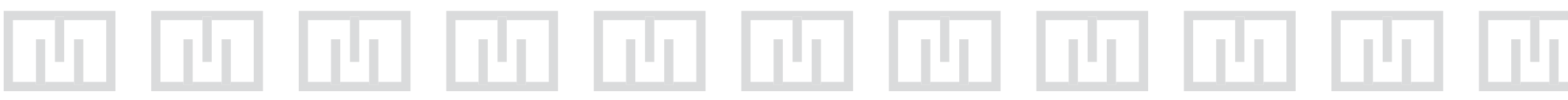

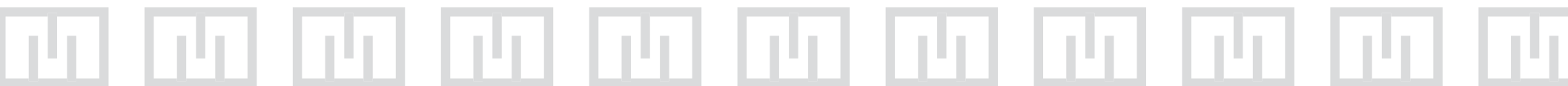

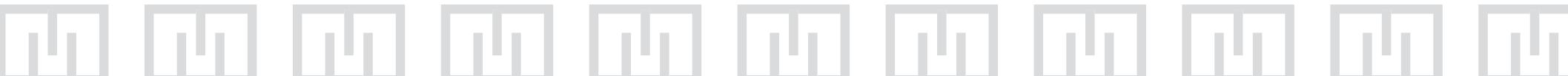

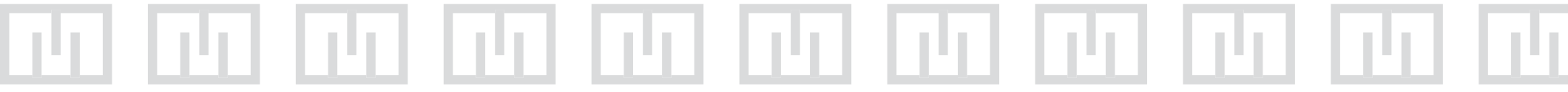

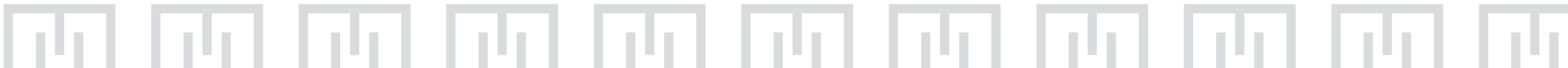

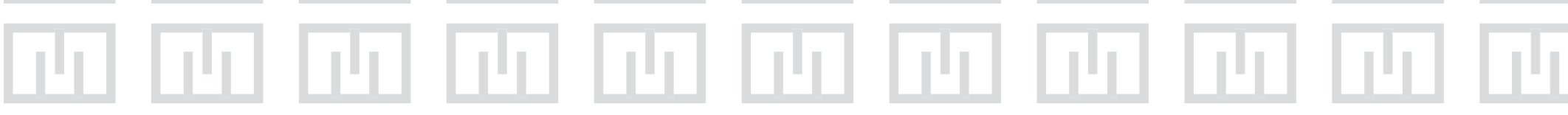

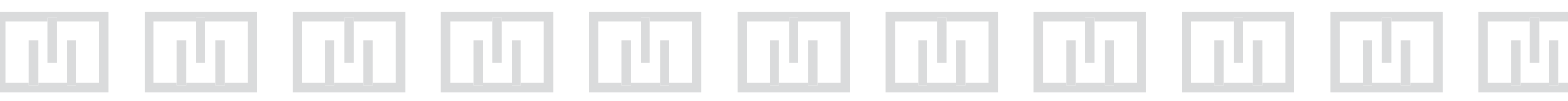

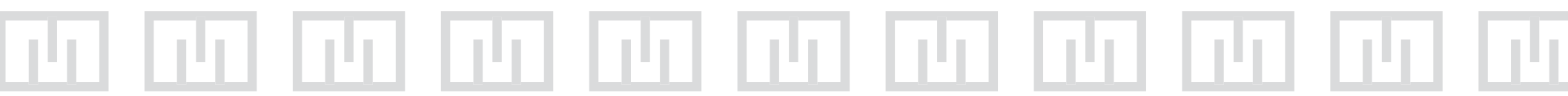
ע (1)

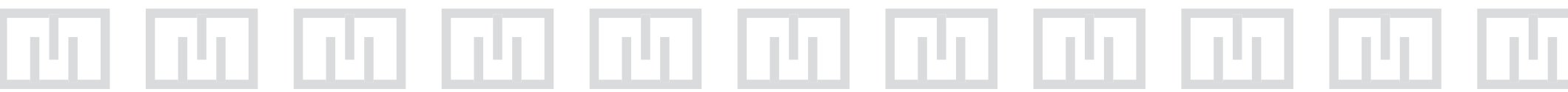

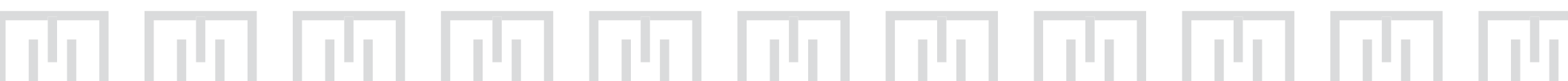

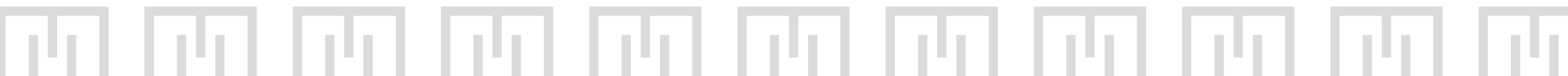

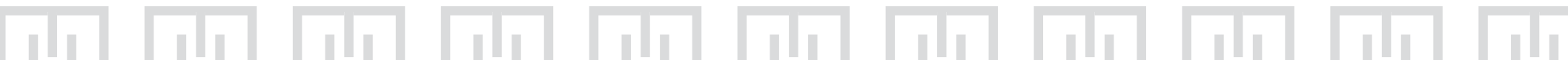

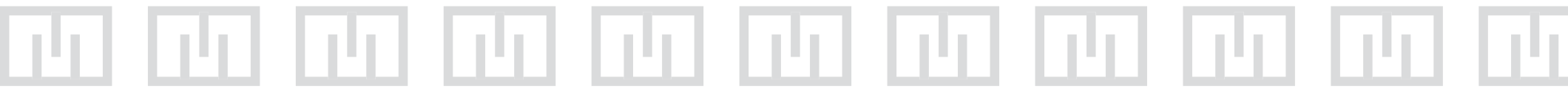

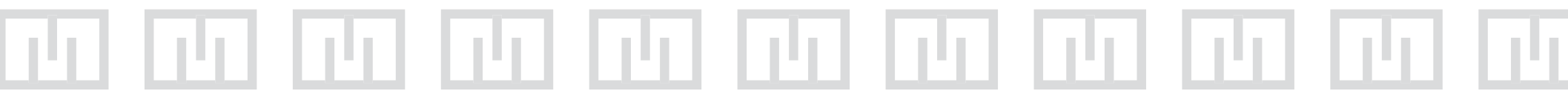

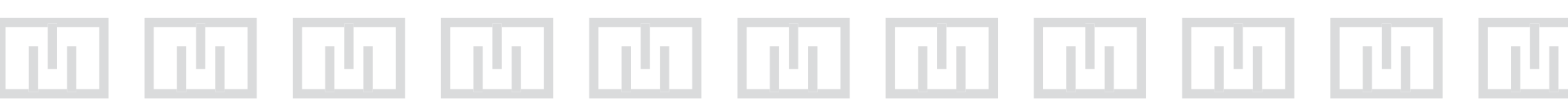

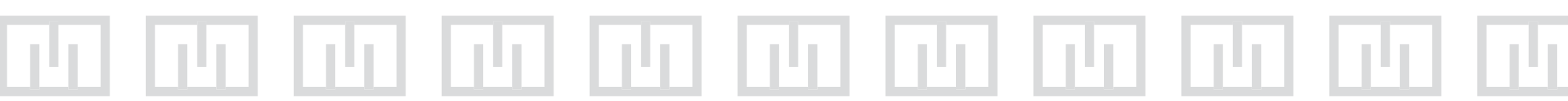

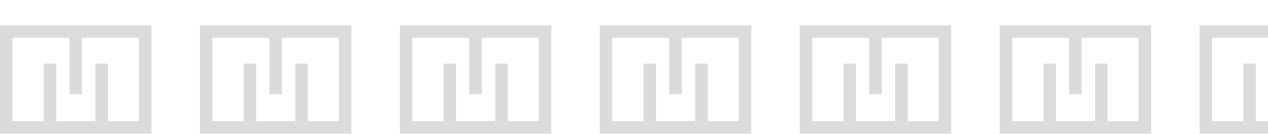

